\title{
A THINKER-BASED APPROACH TO FREEDOM OF SPEECH
}

\author{
Seana Valentine Shiffrin*
}

\section{INTRODUCTION}

Many contemporary autonomy theories of freedom of speech champion the perspective and freedom of just one side of the communicative relation-usually, the speaker or the listener(s). Such approaches seem to neglect or subordinate the autonomy interests of the other relevant parties. Other autonomy theories do not privilege one perspective on the communicative relation over another, but strangely treat the speakers' interests and the listeners' autonomy interests as rather discrete entities-disparate constituents both demanding our attention. Both strands gloss over a source of justification for free speech that both connects the two perspectives and recognizes the wider foundations that underpin their value (by contrast with the more narrow connections drawn between them by democracy theories). Specifically, both approaches celebrate one or more external manifestations of thought but do not focus on the source of speech and cognition-namely the thinker herself - and the conditions necessary for freedom of thought. I submit that a more plausible autonomy theory of freedom of speech arises from taking the free thinker as the central figure in a free speech theory. We should understand freedom of speech as, centrally, protecting freedom of thought.

Hence, in this essay, I propose to sketch a particular sort of autonomy theory of freedom of speech, namely a thinker-based foundation for freedom of speech. Although this account does not capture all of the values of freedom of speech or yield a

* Professor of Philosophy and Pete Kameron Professor of Law and Social Justice, UCLA. For enlightening criticism and commentary, I am grateful to Mark Greenberg, Jeffrey Helmreich, Barbara Herman, Heidi Kitrosser, Terry Stedman, participants in the Columbia Legal Theory Workshop, the Princeton Program in Ethics and Public Affairs and my free speech seminars at UCLA, and, of course, the members of the free speech discussion group from which this paper originates, especially Ed Baker and Steve Shiffrin. Terry Stedman also provided invaluable research assistance. 
comprehensive theory of freedom of speech, a thinker-based foundation can provide a stronger and more coherent foundation for the most important free speech protections than rival free speech theories, including the more common speakerbased or listener-based autonomy theories.

In saying a thinker-based foundation undergirds the most important free speech protections, I mean 'most important' in a normative sense, and not in the sense that they are necessarily acknowledged as such, or at all, in contemporary free speech doctrine. ${ }^{2}$ My paper aims to identify strong theoretical foundations for the protection of free speech but not to provide the best theoretical account of our system or our current practices of protecting (or failing to protect, as the case may be) ${ }^{3}$ free speech. Articulating a theory of free speech along the former, more ideal, lines provides us with a framework to assess whether our current practices are justified or not, as well as which ones are outliers. An ideal theoretical approach also supplies both a measure for reform and some structural components to form the framework to assess new sorts of cases.

1. I have explored some aspects of a thinker-based approach in prior work. See Vincent Blasi \& Seana V. Shiffrin, The Story of West Virginia Board of Education v. Barnette, in CONSTITUTIONAL LAw STORIES 433 (Michael Dorf ed., 2d ed. 2009); Seana Valentine Shiffrin, WhatIis Really Wrong with Compelled Association?, 99 Nw. U. L. REV. 839 (2005) [hereinafter Shiffrin, What Is Really Wrong with Compelled Association?]. I do not mean to represent Vince as endorsing the general thinkeroriented approach I outline above, however. Some other authors have explored aspects of thinker-based approaches as well, although from different angles and with different emphases. See, e.g., Charles Fried, MODERn Liberty 95-123 (2007); Timothy MACKLEM, INDEPENDENCE OF MIND 1-32 (2006); SUSAN WILlIAMS, TRUTH, Autonomy, AND SPEeCH: FEMINIST THEORY AND THE FIRST AMENDMENT 130-229 (2004); Charles Fried, The New First Amendment Jurisprudence: A Threat to Liberty, 59 U. CHI. L. REV. 225 (1992); Dana Remus Irwin, Freedom of Thought: The First Amendment and the Scientific Method, 2005 WIS. L. REV. 1479; Neil M. Richards, Intellectual Privacy, 87 TEX. L. REV. 387 (2008); Christina E. Wells, Reinvigorating Autonomy: Freedom and Responsibility in the Supreme Court's First Amendment Jurisprudence, 32 HARV. C.R.-C.L. L. REV. 159 (1997). See also Immanuel Kant, What is Orientation in Thinking?, in KANT: POLITICAL WRITINGS 237, 247 (Hans Reiss ed., trans. H.B. Nisbet, 2d ed. 1991). Although Ed Baker's writing often suggests a speaker-based approach, in email correspondence about a draft of this paper he indicated that his true sympathies lay with a thinker-based approach. E-mail from Ed Baker to Seana Shiffrin (Feb. 13, 2009) (on file with author).

2. Seana Valentine Shiffrin, Methodology in Free Speech Theory, 97 VA. L. REV. 549 (2011) (defending a normative approach to free speech theory that does not take explanation of extant doctrine as foundational).

3. One free speech howler from the 2009 term around which I would not care to tailor a free speech theory is Holder v. Humanitarian Law Project, 130 S. Ct. 2705, 273031 (2010) (upholding congressional prohibition of assistance to designated terrorist organizations, including its application to mere speech that provides advice on how to petition the U.N. or how to use legal means to resolve conflicts peacefully). 
Which freedom of speech protections figure among the most important is, of course, contested. My position in that debate is that a decent regime of freedom of speech must provide a principled and strong form of protection for political speech and, in particular, for incendiary speech and other forms of dissent, for religious speech, for fiction, art - whether abstract or representational-and music, for diaries and other forms of discourse meant primarily for self-consumption, and for that private speech and discourse, e.g. personal conversations and letters, crucial to developing, pursuing, and maintaining personal relationships. ${ }^{4}$

Further, all of these forms of expression should enjoy foundational protection, by which I mean there should not be a lexical hierarchy of value between them, nor should the protections for some depend dominantly on their playing an instrumental role in securing the conditions for the flourishing practice of another. To put it more pointedly, an adequate free speech theory will avoid the convolutions associated with the more narrow democracy theories of freedom of speech and their efforts to explain why abstract art and music should gain free speech protection. Although a case could be made that the freedom to compose and to listen to Stravinsky is important to developing the sort of open personal and cultural character necessary for democracy to flourish or that it feeds the "sociological structure that is prerequisite for the formation of public opinion," that justification is strained and bizarrely indirect. ${ }^{6}$ In any case, the right of Stravinsky to compose and of

4. These are, of course, theoretically informed, provisional starting points that strike me as highly intuitive, secure, illuminating, and important lodestars. Nonetheless, if a plausible theory cannot be found that supports and explains these judgments or if a more plausible theory would reject them for good reason, these judgments should be revised or discarded. That is, I regard their identification as just an early step in a process aimed at achieving reflective equilibrium and not as fixed or immutable 'results' that must be accommodated, no matter what the other theoretical costs. See JOHN RAWLS, A THEORY OF JUSTICE 17-21, 46-53 (Original ed. 1971) (discussing reflective equilibrium). Further, the argument that follows does not, largely, use these starting points as premises. So, subscription to these starting points is not a precondition for the argument's success; it is merely that their accommodation and explanation seems to be desiderata of a satisfactory theory.

5. See Robert Post, Participatory Democracy and Free Speech, 97 VA. L. REV. 477, $486(2011)$

6. Jim Weinstein offers a refreshingly candid admission of this difficulty. James Weinstein, Participatory Democracy as the Central Value of American Free Speech Doctrine, 97 VA. L. REV. 491, 499 n.45 (2011). No more successful is the argument that democracy theories will protect the arts because to understand one another and to form a conception about what should be a public matter, we must have access to the forms of expression others engage in and deem important. See, e.g., Robert Post, Participatory 
audiences to listen (or to cringe in non-comprehension) should not depend upon whether The Rite of Spring breeds democrats or fascists, or whether it supports, detracts from, or is superfluous to a democratic culture.

A good free speech theory should identify a non-contingent and direct foundation for its protection. On the other hand, protection for commercial and non-press, business corporate speech is a less central matter, one that reasonably may involve weaker protections and may reasonably rely heavily on more instrumental concerns. A good free speech theory should explain why commercial and business corporate speech may be different

Democracy as a Theory of Free Speech: A Reply, 97 VA. L. REV. 617, 621 (2011) ("So long as Brokeback Mountain, and indeed all forms of communication that sociologically we recognize as art, form part of the process by which society ponders what it believes and thinks, it is protected under a theory of the First Amendment that stresses democratic participation.") This justification is circuitous. It is parasitic upon others' developing the art form (which now we must have access to in order to understand them and their preferences) but either: does not provide foundational support for their freedom to develop it, or if it does, the argument lacks a fundamentally and specifically democratic form that is independent of and logically prior to an appeal to the interests of the autonomous thinker.

7. Joshua Cohen offers a far less narrow democratic account of free expression, one grounded in his deliberative democratic approach. His approach shows sensitivity to the interests of the citizen qua thinker and his approach provides a more plausible grounding for art, religious speech, erotic speech, and other forms of speech that are not explicitly or even indirectly political. Joshua Cohen, Freedom of Expression, 22 PHIL. \& PUB. AFF. 207 (1993), reprinted in JoshUA COHEN, PHILOSOPHY, POLITICS, DEMOCRACY 98, 114 20 (2009) [hereinafter Cohen, Freedom of Expression]; Joshua Cohen, Democracy and Liberty, in DELIBERATIVE DEMOCRACY 185 (Jon Elster ed., 1998), reprinted in PHILOSOPHY, POLITICS, DEMOCRACY, supra, at 223, 248-54 [hereinafter Cohen, Democracy and Liberty]; Joshua Cohen, Deliberation and Democratic Legitimacy, in DELIBERATIVE DEMOCRACY 67 (James Bohman \& William Rehg eds., 1997), reprinted in PHILOSOPHY, POLITICS, DEMOCRACY, supra, at 16, 32-34 [hereinafter Cohen, Deliberation and Democratic Legitimacy].

Although our approaches are fairly congenial, Cohen's case for rights of personal, non-political expression is usually voiced in terms of what the citizen "reasonably takes to be compelling considerations" or "substantial reasons" for expression (emphasis added). See, e.g., Cohen, Freedom of Expression, supra note 7, at 115-17; Cohen, Democracy and Liberty, supra note 7, at 248-50. By contrast, I find unnecessary and over-demanding his stress upon agents' having substantial, compelling or obligatory reasons for their particular expression. Putting aside the peculiarly intense drive of the single-minded artist, many citizens' reasons for most of their speech, including a variety of images, melodies, artistic or quotidian thoughts, lack that charge. Nonetheless, in my view, they present no weaker of a case for protection. My aim is to develop an approach that does not rely on the idea that particular, personal expression is protected because its expression reasonably presents itself as akin to, or on a spectrum with, felt obligations of the speaker, interference of which would be unreasonable by the polity, but rather, an approach that is fully consistent with the admission that much personal and artistic speech is banal and unimportant in the grand scheme of things. A broader focus on the condition of the thinker, rather than on the (perceived) significance of the expression, seems better able to satisfy that desideratum. 
and why arguing for their protection may be a less straightforward matter.

Briefly put, I believe these desiderata are best satisfied by a thinker-based free speech theory that takes to be central the individual agent's interest in the protection of the free development and operation of her mind. Legal materials (by which I mean to encompass laws, regulations, court rulings, and resolutions) and government activity inconsistent with valuing this protection are inconsistent with a commitment to freedom of speech. In my view, legal materials or activity may be inconsistent with valuing this protection in three main ways: (1) the legal materials or the government activity may, on their face, ban or attempt to ban the free development and operation of a person's mind or those activities or materials necessary for its free development and operation; (2) the effect of the legal materials, or of the activity, may objectionably interfere with the free development and operation of a person's mind; (3) the rationale for the materials, or the activity, may be inconsistent with valuing this protection.

In developing this position I will proceed from the assumption that, for the most part, we are individual human agents with significant (though importantly imperfect) rational capacities, emotional capacities, perceptual capacities and capacities of sentience - all of which exert influence upon each other. ${ }^{9}$ I will also assume that our possession and exercise of these capacities correctly constitute the core of what we value about ourselves.

I will not say much to defend these assumptions. I do not regard them as especially controversial. (To address the

8. See also Seana Valentine Shiffrin, Speech, Death and Double Effect, 78 N.Y.U. L. REV. 1135, 1164-71 (2003).

9. In some of us, these capacities are fledgling, partial, or compromised. Nonetheless, agents with them have an interest in their development and operation. Although the degree of development and future potential may make some difference in some cases and contexts, I do not think that, at base, a free speech theory delivers fundamentally different results depending upon whether we are discussing children, the mentally disabled, those suffering dementia, or fully formed adults. The most salient context in which degree of development might be thought normatively to make a difference, the schoolroom, seems better explained by reference to time, place, and manner restrictions than to the developmental level of children. This, of course, is a normative claim and one that does not entirely square with doctrinal developments over the last twenty years. For discussions of children and the First Amendment, see Blasi \& Shiffrin, supra note 1; Colin M. Macleod, A Liberal Theory of Freedom of Expression for Children, 79 CHI.-Kent L. Rev. 55 (2004) See generally Symposium, Do Children Have the Same First Amendment Rights as Adults?, 79 CHI.-KENT L. REV. 3 (2004). 
concerns of those who disagree would require a longer digression than seems appropriate here.) Indeed, many popular theories of freedom of speech only make sense if the individual mind and the autonomy of its operation (a notion I will say more about below) are valued and treated with respect. If we did not regard the autonomy of the individual mind as important, it is hard to see why we would value its expression or outputs in the way and to the degree that truth theories or democratic theories value speech. The same holds true of speaker-based and listenerbased theories. ${ }^{10}$ Still, each theory shares the presupposition that the autonomous thinker fundamentally matters; speaker, listener, and democracies theories start from an intermediate point and hone in on one activity of the thinker, rather than on the thinker herself. Reasoning from the standpoint of the thinker and her interests can yield a more comprehensive, unified foundation for much of the freedom of speech protection than is yielded by starting from a more partial intermediate point.

My aim in what follows is to show the supportive connection between valuing ourselves as so described and: (1) valuing speech; (2) valuing freedom of speech; (3) regarding speech as, in some politically and legally normative respects, special. With respect to this last item, contra Fred Schauer, I deny that an autonomy theory of free speech must show that speech is special or unique with respect to its relation to autonomy, in order to justify strong protections for freedom of speech. It may succeed at that justificatory project while articulating values that cast a broader net encompassing other forms of autonomous activity. ${ }^{11}$ Indeed, I regard it as a general strength of autonomy theories that they explain the continuity between speech protections and rights of intimate association. But, although the plausibility of a theory of strong protections for freedom of speech does not depend upon its showing that speech is special, nonetheless, I do think speech occupies a special place in the life and politically germane needs of the autonomous thinker. It is worth showing how it is both special and, at the same time, how it connects to other autonomy interests.

10. Some purely instrumental theories of freedom of speech that focus on the importance of controlling the excesses of state authority may differ on this point.

11. Frederick Schauer, Must Speech Be Special?, 78 Nw. U. L. ReV. 1284 (1984). Some of Post's criticisms of autonomy theories of freedom of speech appear to be versions of the complaint that such theories cannot explain why speech is special. See Post, supra note 5, at 479-81, 484, 487. 


\section{AUTONOMOUS AGENTS AND FREEDOM OF SPEECH}

Having stated my aspirations, let me move on to the argument. I begin with an explicit, albeit perhaps partial, elaboration of the interests of autonomous thinkers.

If we do value ourselves as rational agents with the capacities previously described, then I submit we should recognize a more articulated (though sometimes overlapping) list of interests that emerge from our possession of these valuable capacities.

Namely, every individual, rational, human agent qua thinker has interests in:

\section{a. A capacity for practical and theoretical thought.}

Each agent has an interest in developing her mental capacities to be receptive of, appreciative of, and responsive to reasons and facts in practical and theoretical thought, i.e. to be aware of and appropriately responsive to the true, the false, and the unknown.

\section{b. Apprehending the true.}

Each agent has an interest in believing and understanding true things about herself, including the contents of her mind, and the features and forces of the environment from which she emerges and in which she interacts.

\section{c. Exercising the imagination.}

Rational agents also have interests in understanding and intellectually exploring non-existent possible and impossible environments. Such mental activities allow agents the ability to conceive of the future and what could be. Further, the ability to explore the non-existent and impossible provides an opportunity for the exercise of the philosophical capacities and the other parts of the imagination.

\section{d. Becoming a distinctive individual.}

Each agent has an interest in developing a personality and engaging more broadly in a mental life that, while responsive to reasons and facts, is distinguished from others' personalities by individuating features, emotions, reactions, traits, thoughts, and experiences that contribute to a distinctive perspective that embodies and represents each individual's separateness as a person.

12. See Jed Rubenfeld, The Freedom of Imagination: Copyright's Constitutionality, 112 YALE L.J. 1, 38-39 (2002). 


\section{e. Moral agency.}

Each agent has an interest in acquiring the relevant knowledge base and character traits as well as forming the relevant thoughts and intentions to comply with the requirements of morality. (This interest, of course, may already be contained in the previously articulated interests in developing the capacity for practical and theoretical thought, apprehending the true, and exercising the imagination (a-c)).

\section{f. Responding authentically.}

Each agent has an interest in pursuing (a-e) through processes that represent free and authentic forms of internal creation and recognition. By this, I mean roughly that rational agents have an interest in forming thoughts, beliefs, practical judgments, intentions and other mental contents on the basis of reasons, perceptions, and reactions through processes that, in the main and over the long term, are independent of distortive influences. In saying these processes are independent of distortive influences, I mean they do not follow a trajectory fully or largely scripted by forces external to the person that are distinct from the reasons and other features of the world to which she is responding. This is the intellectual aspect of being an autonomous agent. So too agents have an interest in revealing and sharing these mental contents at their discretion, i.e. at the time at which those contents seem to them correct, apt, or representative of themselves as well to those to whom (and at that time) such revelations and the relationship they forge seem appropriate or desirable.

\section{g. Living among others.}

Each rational, human agent has an interest in living among other social, autonomous agents who have the opportunities to develop their capacities in like ways. Satisfaction of this interest does not merely serve natural desires for companionship but crucially enables other interests of the agent qua thinker to be achieved, including the development and recognition of a distinctive self and character, the acquisition and confirmation of knowledge, and the development and exercise of moral agency.

\section{h. Appropriate recognition and treatment.}

Each agent has an interest in being recognized by other agents for the person she is and having others treat her morally well. 
This list may not be exhaustive, but I believe it identifies some of the more foundational and central interests that agents have, independent of their specific projects, interests, and desires, but just in virtue of their capacities for thought, broadly understood to include autonomous deliberation and reactions, practical judgment, and moral relations. Briefly summarized, these are interests in self-development, self-knowledge, knowledge of others, others' knowledge of and respect for oneself, knowledge of the environments in which one interacts, opportunities for the exercise of one's intellectual capacities including the imagination, and the intellectual prerequisites of moral relations. ${ }^{13}$

Speech, and free speech in particular, are necessary conditions of the realization of these interests. First, given the opacity of our minds to one another, speech and expression are the only precise avenues by which one can be known as the individual one is by others. If what makes one a distinctive individual qua person is largely a matter of the contents of one's mind, ${ }^{14}$ to be known by others requires the ability to transmit the contents of one's mind to others. Although some information about one's thoughts and beliefs may be gleaned from observation, such inferences are typically coarse-grained at best and cannot track the detail and nuance of the inner life of the observed. Communication of the contents of one's mind primarily through linguistic means, but also through pictorial, or even musical representation, uniquely furthers the interest in being known by others. It thereby also makes possible complex forms of social life. ${ }^{15}$ Further, it helps to develop some of the

13. In other work, I have argued that it is a mandatory, central (and fully liberal) aim of law to accommodate and facilitate individuals' ability to engage in moral agency. See Seana Valentine Shiffrin, Inducing Moral Deliberation: On the Occasional Virtues of Fog, 123 HARV. L. REV. 1214, 1222-29 (2010) [hereinafter Shiffrin, Inducing Moral Deliberation]; Seana Valentine Shiffrin, The Divergence of Contract and Promise, 120 HARV. L. REV. 708, 713-19 (2007) [hereinafter, Shiffrin, Divergence]. Although I have mainly focused on other legal contexts of moral accommodation and facilitation, free speech protections may represent the most important legal context for the legal support of agents' moral capacities. See also Seana Valentine Shiffrin, Compelled Association, Morality, and Market Dynamics, 41 LOY. L.A. L. REV. 317, 324-26 (2007) [hereinafter Shiffrin, Compelled Association].

14. I do not mean what individuates one as a creature. In that respect, physical features including one's genetic composition and perhaps other physical, non-mental facts may be important.

15. This consideration figured large among the motivations behind Kant's views about truthfulness and lying. See Immanuel Kant, Of Ethical Duties Towards Others, and Especially Truthfulness, in LECTURES ON ETHICS 200-209 (Peter Heath \& J.B. Schneewind eds., trans. Peter Heath, 1997). Of course, individuals may not fully know themselves and, further, may be self-deceived. Hence, they may not be fully equipped to 
capacities prerequisite to moral agency because successful communication demands having a sense of what others are in a position to know and understand. Practicing communication initiates the process of taking others' perspective to understand what others know and are in a position to grasp.

Being known by others as the distinct individual one is is important in itself. It is also essential for one to be fully respected by others. Further, having access to the contents of others' minds (at their discretion) is essential for being able to respect them, at least insofar as some forms of respect and other moral duties involve understanding and respecting individuals as separate persons and in light of features of their individuality, including their reasons, aims, and needs. Moreover, other forms of moral activity, as well as appreciation of the moral activity of others, require some recognition of agents' motives.

Furthermore, I suspect that one cannot fully develop a complex mental world, identify its contents, evaluate them, and distinguish between those that are merely given and those one endorses, unless one has the ability to externalize bits of one's mind, formally distance those bits from one's mind, identify them as particulars, and then evaluate them to either endorse, reject, or modify them. For many people, some thoughts may only be fully identified and known to themselves if made linguistically or representationally explicit. Many find that difficult to do using merely mental language, especially with sufficiently complex ideas; one has to externalize what the thoughts are through verbal or written speech or through other forms of symbolic representation to identify them completely (and sometimes to form them at all), a prerequisite to evaluating their contents. Other thoughts and methods of tracking one's environment over time require some form of external representation because of the frailties of the human memory; to form the complex thought, one needs the device of external representation to keep track of portions of it over time. ${ }^{16}$ The ability and opportunity to generate external representations may

share all of the contents of their minds with others and to enable others fully to know themselves directly through testimony. This does not diminish my point. Even when people are self-deceived, what they take to be their beliefs, emotions and other mental contents is an important aspect of who they are; further, sharing these contents with others and confronting the reactions of others and their observations of one's contrary behavior is often crucial to resolving and eliminating self-ignorance and self-deception.

16. Tyler Burge, Computer Proof, Apriori Knowledge, and Other Minds: The Sixth Philosophical Perspectives Lecture, 32 NOÛs SUPPL. 12 1, 10-13, 19-22, $27-28$ (1998); Tyler Burge, Memory and Persons, 112 PHIL. REV. 289, 300-03, 314-21 (2003). 
both make public what has already fully formed in the mind and may render possible the formation of new sorts of thoughts that cannot take full form in our limited mental space. ${ }^{17}$

Of course, it is not merely the development and identification of one's thoughts that requires the use of representation and external articulation. To pursue our interest in forming true beliefs about ourselves and our environment, we need the help of others' insights and beliefs, as well as their reactions and evaluative responses to our beliefs. Others can only have the basis for responding, and the means to respond with the sort of precision necessary to be helpful, if they are able to use speech.

My argument that rational human thinkers need access to other thinkers under conditions in which their mental contents may be known with some degree of precision, explicitly recognized as such, and reacted to, is partially but poignantly confirmed by the evidence of the disastrous effects of involuntary solitary confinement. Prisoners in solitary confinement deteriorate mentally and emotionally. They progressively lose their grip on reality, suffering hallucinations and paranoia, and many become psychotic." "Human beings rely on social contact with others to test and validate their perceptions of the environment. Ultimately, a complete lack of social contact makes it difficult to distinguish what is real from what is not or what is external from what is internal." ${ }^{19}$ Prisoners subject to solitary confinement suffer terrible depression, despair and anxiety; moreover, their emotional control and stability wane and their abilities to interact with others atrophy. ${ }^{20}$

Of course, prisoners in solitary confinement endure more than just the lack of conversation and the absence of interlocutors; they lack fundamental forms of control over their lives, other sorts of interactions with persons, and other forms of

17. See also MACKLEM, supra note 1, at 1-32.

18. See, e.g., Bruce A. Arrigo \& Jennifer Leslie Bullock, The Psychological Effects of Solitary Confinement on Prisoners in Supermax Units: Reviewing What We Know and Recommending What Should Change, 52 INT'L J. OF OFFENDER THERAPY \& COMP. CRIMINOlOGY 622, 627 (2008); Craig Haney, Mental Health Issues in Long-Term Solitary and "Supermax" Confinement, 49 CRIME \& DELINQ. 124, 130-32 (2003).

19. Arrigo \& Bullock, supra note 18 , at 7 (citing the work of Haney, supra note 18). Similar evidence presents itself about the effects of uncorrected hearing loss. Stig Arlinger, Negative Consequences of Uncorrected Hearing Loss: A Review, 42 INT'L J. OF AUDIOLOGY 2S17, 2S17-20 (2003) (reporting that hearing loss may reduce intellectual and cultural stimulation, give rise to changes in the central nervous system, and may affect the development of dementia).

20. See Haney, supra note 18. 
perceptual access to reality. But, most other prisoners lack this sort of control and lack broader forms of access to the world and yet do not suffer the degree of devastation to mental function that prisoners in solitary confinement do. "Whether in Walpole or Beirut or Hanoi, all human beings experience isolation as torture." 22 What seems to push them over the edge is the absence of regular, bilateral communication. My worry is that to forbid or substantially to restrict free expression is not tantamount to solitary incarceration but lies on a spectrum with it: it is to institute a sort of solitary confinement outside of prison but within one's mind.

So, in short, the view I am attracted to is that it is essential to the appropriate development and regulation of the self, and of one's relation to others, that one have wide-ranging access to the opportunity to externalize one's mental contents, to have the opportunity to make one's mental contents known to others in an unscripted and authentic way, and that one has protection from unchosen interference with one's mental contents from processes that would disrupt or disable the operation of these processes. That is to say, free speech is essential to the development and proper functioning of thinkers.

Further, because moral agency involves the ability to take the perspective of other people and to respond to their distinctive features as individuals, including some of their mental contents, then free speech also plays a foundational and necessary (though not sufficient) role in ensuring citizens develop the capacity for moral agency and have the opportunities and information necessary to discharge their moral duties. Politically, these arguments should resonate with us, yielding an argument for constitutional protection for freedom of speech, both from respect for the fundamental moral rights of the person and also because, as I have argued elsewhere, a wellfunctioning system of social cooperation and justice presupposes that the citizenry, by and large, have active, well-developed moral personalities. ${ }^{23}$ The successful operation of a democratic polity, as well as its meaningfulness, would also seem to depend

21. See id. at 125 added).

2. Atul Gawande, Hellhole, THE NEW Yorker, Mar. 30, 2009, at 36 (emphasis

23. Shiffrin, Inducing Moral Deliberation, supra note 13, at 1231-32. See also JOHN StuART MiLl, CONSIDERATIONS ON REPRESENTATIVE GOVERNMENT 24-25 (Currin Shields ed., 1958); RAWLS, supra note 4, at 395-587. 
upon citizens' generally having strong and independent capacities for thought and judgment.

This view makes no important distinction, at the foundations, between communication about aesthetics, one's medical condition and treatment, ${ }^{24}$ one's regard for another, one's sensory perceptions, the sense or lack thereof of the existence of a God, or one's political beliefs. All of these communications serve the fundamental function of allowing an agent to transmit (or attempt to transmit so far as possible) the contents of her mind to others and to externalize her mental contents in order to attempt to identify, evaluate, and endorse or react to given contents as authentically her own; further, they allow others to be granted access to the information necessary to appreciate the thinker, on voluntary terms, and to forge a full human relation with her. One's thoughts about political affairs are intrinsically and $e x$ ante no more and no less central to the human self than thoughts about one's mortality or one's friends; insofar as a central function of free speech is to allow for the development, exercise, and recognition of the self, there is no reason to relegate the representation of thoughts about personal relations or self-reflection to a lesser or secondary category. Pictorial representations and music (and not merely discourse about them) should also gain foundational protection because they also represent the externalization of mental contents, contents that may not be accurately or well-captured through linguistic means; after all, not all thoughts are discursive or may be fully captured through discursive description. ${ }^{25}$

24. Respect for this right is far from a given. Prita Mulyasari was recently incarcerated in Indonesia for three weeks of pre-trial detention on charges of internet defamation after she sent an email to friends complaining about a wrongful diagnosis at a local hospital. After an international campaign in her defense, she was acquitted but the government is appealing her acquittal and seeking a 6 month prison sentence. See Norimitsu Onishi, Trapped Inside a Broken Judicial System after Hitting Send, N.Y. TIMES, Dec. 5, 2009, at A6; Turning Critics Into Criminals: The Human Rights Consequences of Criminal Defamation Law in Indonesia, HUMAN RigHTS WATCH, 5, 26-28 (May 2010), available at http://www.hrw.org/node/90023 (discussing other criminal defamation cases for other consumer complaints).

Indonesia imposes criminal penalties for defamation, enhancing them if the communication is sent over the internet. Truth, on its own, is not a standard defense. Whether it is permitted at all seems to be a matter of the judge's discretion. Further, defendants seeking to use the truth defense in cases not involving public officials must bear the burden of proof and must show that the defamatory statement was offered from necessity or 'in the general interest.' Pursuing an unsuccessful truth defense may subject the defendant to an even harsher sentence of up to four years in prison. HUMAN RIGHTS WATCH, supra note 24, at 16-17.

25. See e.g., Frank Jackson, Epiphenomenal Qualia, 32 PHIL. Q. 127, 128-30, 133-36 (1982); Frank Jackson, What Mary Didn't Know, 83 J. PHIL. 291 (1986). 
On the other hand, this approach can render sensible the notions that non-press, business corporate and commercial speech may be different and that their protection may assume a weaker form, resting upon separate, more context-dependent and instrumental foundations. ${ }^{26}$ First, business corporate speech does not involve in any direct or straightforward fashion the revelation of individuals' mental contents. ${ }^{27}$ Corporate-tocorporate as well as corporate-to-individual speech often bear only an indirect relation to the revelation and development of the thinker or the intellectual, emotional, or moral relations between thinkers. Of course, thinkers may have an interest in access to corporate speech because corporate and commercial speech may report information about one's given environment, but, in other circumstances, the point of corporate speech, as well as other commercial speech, is to alter the environment, e.g. to manufacture desire, not to report it.

To be sure, however, altering the environment is also the aim of advocacy speech by individuals as well. That aim in no way diminishes the protection that should be afforded to it. Advocacy speech represents a form of exercise of thinkers' interests in developing their moral agency and in treating one another well by attempting to discern and to persuade others of what each of us or what we together should think and do. By contrast, non-press, business corporate and commercial speech, by design, issue from an environment whose structure does not facilitate and, indeed, tends to discourage the authentic expression of individuals' judgment. As Ed Baker has argued, the competitive structure of the economic market and the narrowly defined aims of the corporate or commercial entity place substantial pressures on the content of corporate and commercial speech. So too may the internal structural design of

26. For one example of its context-dependence on other features of the economic climate and our system of economic regulation, see Shiffrin, Compelled Association, supra note 13 , at $324,327$.

27. See, e.g., Citizens United v. Fed. Election Comm'n, 130 S. Ct. 876, 971 (2010) (Stevens, J., dissenting) (discussing the differences between corporations and human beings and the distance between corporate speech and any individual points of view); C. Edwin Baker, The First Amendment and Commercial Speech, 84 IND. L.J. 981, 987-89 (2009) (stressing that commercial corporations are limited forms of entities created for instrumental reasons and that the people who operate within them do not act fully autonomously); Steven H. Shiffrin, The First Amendment and Economic Regulation: Away from a General Theory of the First Amendment, 78 Nw. U. L. REV. 1212, 1246 (1983) (discussing the structure of the corporation and the distance between its speech and the views of its shareholders). 
the corporation. ${ }^{28}$ In Baker's view, their content has a 'forced profit orientation,' and does not represent a 'manifestation of individual freedom or choice', ${ }^{29}$ in my somewhat weaker terms, external environmental pressures render more tenuous any charitable presupposition that such speech is sincere, authentic, or the product of autonomous processes. As I have argued elsewhere, Baker's starkly-put position may involve a degree of over-generalization given market imperfections, market actors who are true believers, and market actors using the market and speech within it to further external and sincere moral goals. ${ }^{30}$ Nonetheless, I concur with him that the market's structure tends "very strongly [to] determine [corporate and commercial] speech content." ${ }^{\prime 31}$ These distortive influences render more precarious the claims that strong presumptions against speech regulation in this domain reliably serve the interests of the thinker-quaspeaker or the thinker-qua-listener as the recipient of such communications. Together, these considerations provide reason to treat non-press, business corporate and commercial speech as non-standard cases within a free speech domain and justifiably, depending on context and content, often to treat such speech as permissible targets of a more comprehensive scheme of economic regulation. ${ }^{32}$

\section{COMPARING A THINKER-BASED APPROACH TO OTHER AUTONOMY APPROACHES}

This approach, one that showcases freedom of thought and the needs of thinkers as such as the central theme of a free speech perspective, is compatible with many of the traditional insights associated with speaker-based and listener-based theories (and with democracy and truth theories for that matter). All of these approaches, however, work from an overly narrow foundation or they start by valorizing one manifestation of free

28. See Shiffrin, supra note 27, at 1247.

29. See C. Edwin BAKER, Human Liberty AND Freedom of SPEeCH 196, 204 (1989); C. Edwin Baker, Paternalism, Politics, and Citizen Freedom: The Commercial Speech Quandary in Nike, 54 CASE W. RES. L. REV. 1161, 1163 (2004); Baker, supra note 27 , at $985-87$.

30. See Shiffrin, Compelled Association, supra note 13, at 320

31. Id.

32. See also Baker, supra note 27 , at 994 . I have assumed throughout this part of the discussion that the government's motives in regulating commercial or business corporate speech would be permissible ones, that is to say that they were not driven by a rationale that is inconsistent with valuing the autonomous operation of the mind. The requirement that the government's rationale must be a permissible one, as I specify above, is not suspended in this domain (or any other). 
thought, while neglecting other manifestations that are no less important. Although the ability to externalize one's mental contents through speech is of prime importance on this account, it would make no sense to give it pride of place over ensuring that others could listen or take in these transmissions or over the protection of one's rational processes from interference or disruption.

Because this account derives the basic free speech protection from the foundational interests of the autonomous agent qua thinker, it therefore, rests on sparer assumptions than other autonomy accounts, such as Ed Baker's, that revolve around the autonomous agent qua self-governor. ${ }^{33}$ Whether in its substantive form (the agent as a person with the capacity "to pursue successfully the life she endorses") or its formal conception (the agent with "the authority to make decisions about her own meaningful actions [and resources]"), 34 Baker's ideal invokes an attractive model towards which to aspire, but utilizes unnecessarily controversial assumptions.

For instance, I do not believe that the autonomy case for protecting free speech hinges upon whether we have (or should have or should value) the full panoply of executive skills and control over our actions that the broader ideal of self-authorship and self-governance involves. We may have all the interests I identify (along with their capacities to pursue them) even if we lack the ability or authority to implement our decisions. Rightfully detained prisoners will lack both these features but, in my view (if not the Court's), ${ }^{35}$ enjoy the relevant moral right of

33. See BAKER, HUMAN LIBERTY AND FREEDOM OF SPEECH, supra note 29, at 4769; Baker, supra note 27, at 990 (identifying autonomy in terms of embodying values in action). See generally Edwin Baker, Autonomy and Free Speech, 27 CONST. COMMENT. 251 (2011) [hereinafter Baker, Autonomy].

34. See Edwin Baker, Autonomy, supra note 33, at 253, 54.

35. See Beard v. Banks, 548 U.S. 521, 530-33 (2006) (plurality opinion) (upholding ban on access to newspapers, magazines, and personal photographs by prisoners in the most restrictive level of incarceration); Turner v. Safley, 482 U.S. 78, 89 (1987) ("[W]hen a prison regulation impinges on inmates' constitutional rights, the regulation is valid if it is reasonably related to legitimate penological interests.”); Bell v. Wolfish, 441 U.S. 520, 548-52 (1979) (upholding ban on pretrial detainees receiving hardback books by mail unless sent directly by the publisher or a bookstore); Jones v. N.C. Prisoners' Labor Union, Inc., 433 U.S. 119, 129-33 (1977) (upholding ban on bulk mailing and inmate-toinmate solicitation to join prisoner's union); Pell v. Procunier, 417 U.S. 817, 822-28 (1974) (upholding ban on prisoners initiating interviews with the press). For critical commentary on the low protection afforded to prisoners' First Amendment rights see James E. Robertson, The Rehnquist Court and the "Turnerization" of Prisoners' Rights, 10 N.Y. CITY L. REV. 97 (2006); The Supreme Court, 2005 Term-Leading Cases, 120 HARV. L. REV. 125, 263 (2006). 
freedom of speech. Skepticism about the broader ideal therefore should not impugn the more narrowly tailored, thinker-centered case for free speech protections. ${ }^{36}$ Further, a thinker-based approach is better positioned to undergird a more expansive free speech protection, or at least to do so in a more direct and obvious fashion, because our imagination and thoughts range more widely than our capacity for self-governance and selfauthorship (at least if the latter is construed to involve selfregarding action and conduct). We are able to think and consider topics and subjects that have no specific and direct relation to ourselves and our pursuit of a life we endorse.

Explicitly making the thinker the central figure of free speech (as compared to focusing on the listener, the speaker, the self-governor or the functioning of the polity) may make a difference as far as what dangers and threats to free speech present themselves as salient. So, for example, although I find Tim Scanlon's emphasis on sovereignty of deliberation in the Millian principle at the center of his early listener-based theory highly congenial, its focus on the listener may distract us from equally significant forms of regulation that tamper with the sovereignty of deliberation but that are not directly targeted at interfering with a speaker-listener relation. ${ }^{37}$ Scanlon's Millian principle states:

[C]ertain harms which, although they would not occur but for certain acts of expression, nonetheless cannot be taken as part of a justification for legal restrictions ... (a) harms to certain individuals which consist in their coming to have false beliefs as a result of those acts of expression; (b) harmful consequences of acts performed as a result of those acts of expression, where the connection between [them] consists merely in the ...expression le[a]d[ing] the agents to believe ... these acts to be worth performing. ${ }^{38}$

36. Further, arguing just from the foundational interests of the thinker as such does not elicit the same worries regarding why speech in particular merits special, strong protection.

37. See Thomas Scanlon, A Theory of Freedom of Expression, 1 PHIL. \& PUB. AFF. 204 (1972) reprinted in T.M. SCANLON, THE DifFICUlTY OF TOLERANCE 6, 14-15 (2003). Scanlon subsequently criticized the Millian principle on other grounds than I explore here and embraced a modified, but broader, theory of freedom of speech that, inter alia, offers primary recognition to speaker and audience interests. T.M. Scanlon, Jr., Freedom of Expression and Categories of Expression, 40 U. PITT. L. REV. 519 (1979), reprinted in SCANLON, supra, at 84.

38. Scanlon, supra note 37, at 213. 
Although the insulation of the agent's opportunity to form beliefs and opinions of her own is central to the thinker-based perspective, Scanlon's Millian principle-as stated-has its limitations as a form of protection of the thinker. From a freedom of thought perspective, such a principle is underinclusive in an important respect. ${ }^{39}$ It is unclear why we should protect only autonomous or authentic processes from efforts to interfere with belief and conclusion formation. Should we not also ensure that regulations are not propounded on the grounds that speech will yield emotional reactions of one sort or another or that speech will induce sensory reactions of one sort or another? Aren't these processes also central to human thought at least?

Moreover, Scanlon's principle only reaches and condemns regulation aimed at preventing the formation of false beliefs and practical judgments as consequences of expression. It does not directly speak to the wrongfulness of regulations or government activity aimed at instilling beliefs, attitudes, or reasons through compulsion, subliminal manipulation, or other efforts to circumvent rational deliberation.

Finally, it doesn't directly recognize the significance that assuming the role of speaker may have to an agent's own rational development and cognition. Expanding the theory to correct these forms of under-inclusion would not be, I take it, antithetical to the spirit of Scanlon's original approach. ${ }^{40}$ Nonetheless, an explicitly thinker-oriented approach more naturally yields a comprehensive explanation of what is troubling about thought control, efforts at thought control, as well as other sorts of efforts to disrupt the free operation of the

39. The Millian principle may be overinclusive in the following respect: the principle as stated does not provide a clear line to distinguish between false beliefs that result from fraud or intentional misrepresentation and false beliefs that result from sincere communication (but poor judgment, understanding or perception on the part of the speaker or the listener). The former may reasonably count as harms, I submit, on the grounds that a thinker-based view of freedom of speech provides no foundational protection for speech that aims to distort and control the thinker's rational processes of tracking and understanding her environment. Again, I doubt Scanlon would be hostile to this distinction, as suggested by his apparent friendliness to at least some sorts of defamation actions, id. at 209, and his later criticism in Freedom of Expression and Categories of Expression of the Millian principle for failing to allow laws on deceptive advertising. Scanlon, Jr., supra note 37 , at 532. As originally stated, though, the Millian principle does not clearly make room for defamation liability.

40. See, e.g., SCANLON, supra note 37, at 91-92 (observing the audience's interest "in having a good environment for the formation of one's beliefs and desires" and offering criticisms of subliminal speech). 
mind, whether or not such efforts also happen to operate through a mode of interfering interpersonal communication.

For example, as Vince Blasi and I argued at greater length elsewhere ${ }^{41}$ focusing on freedom of thought as such may yield a more straightforward account of the protection in West Virginia State Board of Education v. Barnette. ${ }^{42}$ It is not clear that the compelled pledge, so long as its origins are transparent, restricts listener opportunities, nor does its motivation violate strictures on respecting listeners and their deliberative capacities. Further, although it seems clear that the compelled pledge violates the free speech rights of the party who must speak the pledge, it is less clear that the standard themes that have occupied speakeroriented theories are squarely engaged here. So long as it is clear the pledge is compelled and so long as the speaker may disavow the pledge, the speaker's ability to express herself faithfully is arguably not seriously abridged. ${ }^{43}$ The speaker will not be misunderstood by reasonable observers. Although reciting others' speech may not be a part of one's project of self-creation, so long as others' uptake isn't disrupted and so long as the compelled speech is not especially time consuming, focusing on the speaker-as such-seems strained. A more straightforward

\footnotetext{
41. See Blasi \& Shiffrin, supra note 1.

42. 319 U.S. 624 (1943).

43. Of course, the necessity of correcting a false impression conveyed to an audience that does not understand the significance of the speech being compelled may impinge upon the speaker's interest in remaining silent with respect to the pledge and the sentiments and commitments expressed therein; necessarily, the interests in selfexpression must include the ability to gather one's thoughts and engage in self-creation at one's own pace. There is something to this point but I am not sure that it carries enough significance to bear the full weight of the Barnette protection. Correcting a misimpression only requires explaining the significance or fact of compulsion; it does not require the speaker to make up her mind or reveal anything substantive about the pledge. This point, however, may be less persuasive in contexts in which any sort of correction or explanation may implicitly reveal some reservations about the pledge and such revelations would be socially or politically dangerous. Still, I assume the Barnette protection holds even for compelled speech that is less fraught or that is compelled in less charged contexts. See, e.g., Wooley v. Maynard, 430 U.S. 705 (1977).

In any case, it is unclear how much of the substance, whether the positive protection or the negative limits, of the First Amendment protection should revolve around how unreasonable people might interpret the significance of a speech performance. For example, the fact that unreasonable people might take my friend's speech to represent my own views and that their misunderstanding might prompt me to speak on a topic about which I'd prefer to remain silent does not begin to ground an argument that I have a right that my friend not speak in a way that may mislead the unreasonable interpreters. The republishing libel doctrine also wanders a little too close for my comfort to the view that the limits of the First Amendment may be dictated by the unreasonable reactions of readers. See, e.g., RESTATEMENT (SECOND) OF TORTS § 578 (1977).
} 
explanation would not focus predominantly on either side of the speaker-audience relationship.

What seems most troubling about the compelled pledge is that the motive behind the regulation, and the possible effect, is to interfere with the autonomous thought processes of the compelled speaker. Significantly, the compelled speaker is also a compelled listener and is compelled to adopt postures that typically connote identification with her message. The aim, and I believe the potential effect, is to try to influence the speaker to associate herself with the message and implicitly to accept it, but through means that bypass the deliberative faculties of the agent. Compelled speech of this kind threatens (or at least aims) to interfere with free thinking processes of the speaker/listener and to influence mental content in ways and through methods that are illicit: nontransparent, via repetition, and through coercive manipulation of a character virtue, namely that of sincerity, that itself is closely connected to commitments of freedom of speech.

Another advantage of a thinker-centered approach is that it yields a distinctive approach to freedom of association that both explains its centrality and depicts the relation between 'intimate' and 'expressive' as continuous. Again, the approach is not antithetical to other theories of freedom of speech, e.g. speakerbased or listener-based theories. But, occupying a thinker-based perspective may orient one more immediately to the centrality of association than other theories which may lead one to value association through a more circuitous route. Even once one adopts a capacious view of the content covered by a free speech norm, speaker-oriented theories have tended to think of the point of associations as bundles of speakers who come together to amplify their speech-to render it louder or to garner more attention for their positions. The model has been to think of speakers as having a prior message that brings them together and that the associations facilitate more effective, clearer communication of these ideas, formed prior to association. The association is a conduit or a pass through: it enhances the effectiveness of the message but plays little formative role with respect to the actual speech.

A thinker-based view of the sort I have been sketching identifies, at least more immediately, the role of associations in a free speech theory. If, as a general matter, our intellectual development and, indeed, our basic sanity depends upon our communicative interaction with others, and, if we conceive of the function of speech as critical to this development, we are 
more likely to be attuned to the ways that associations serve as sites of idea formation and development, and to recognize the ways in which the development (and not merely the broadcasting) of content occurs through mutual collaboration and mutual influence in explicit and implicit ways. Such an approach would not focus predominantly on whether regulations affect the message of an association but on whether regulations interfere with the ability of associations to function as sites for mutual cognitive influence. ${ }^{44}$

\section{WHAT MAKES SPEECH SPECIAL?}

I observed earlier that it seems to me to be a positive feature, rather than an embarrassment, of a speech theory that it can show the compatibility of and even the continuity between different core protections of individual autonomy. At the same time, it does seem as though speech is special in some way. An attractive free speech theory should draw some normative distinction between speech as an exercise of autonomy and at least some other behaviors that are exercises of autonomy; although some forms of autonomous action should perhaps gain the same high level of legal protection as free speech, not all autonomous action should. An attractive free speech theory will help to make some sense of the divide.

With respect to the first desideratum of making sense of the continuity, it strikes me as a strength of the thinker-based approach that it renders the penumbra theory of Griswold ${ }^{45}$ and $R_{0} e^{46}$ sensible. First, certain substantive due process protections provide the preconditions for a meaningful free speech protection. If we accept the First Amendment and its justifications and we accept that our form of rational agency requires social connections to develop and flourish, then we must provide for safe havens for thought, communication, and mutual influence: the relevant forms of safety come both in numbers (i.e. having associates with whom one may share thoughts and who may witness what happens to one) and in the ability to select with whom and in what ways one will share fundamental forms of intimacy. If the state could prevent intimate associations or if it could require them to occur

44. I develop an argument of this kind in greater detail in Shiffrin, What Is Really Wrong with Compelled Association?, supra note 1.

45. Griswold v. Connecticut, 381 U.S. 479 (1965).

46. Roe v. Wade, 410 U.S. 113 (1973). 
(rendering the connection forced and inauthentic), it would obstruct individuals' ability to forge the sort of authentic social connections essential for the development and maintenance of the personality and the free intellect.

Second, the central substantive due process protections are extensions of the values protected by freedom of speech. Sexual intimacy, e.g., expresses and may reveal any of a variety of mental states towards another: in the good cases, feelings of love, affection or at least lusty attraction.

But although (free) sexual intimacy and speech are both exercises of autonomy, both are not standard forms of communication or transmission of mental content; hence my remark that many substantive due process protections are extensions of the values protected by a free speech principle, rather than instantiations of it. A kiss typically expresses a happy reaction, attraction, or a warm attitude, where here I mean to invoke the sense of 'express' that is not synonymous with 'communicate' but rather that means to display and to manifest, rather than just to transmit the fact of or to communicate. ${ }^{47}$ Although the mental attitude may be inferred from it, the kiss is not typically deployed merely to convey the fact of its existence. It can be used that way but its communicative use is parasitic upon the connotations of its expressive function.

This, of course, is a fraught distinction ${ }^{48}$ but it is one that I think has a point that connects to two of the reasons why speech

47. Philosophers of language often use 'expressives' (and its cognate verb) to refer to speech acts that do more than convey content but also manifest it in a more active, direct way. See, e.g., John R. Searle, A Taxonomy of Illocutionary Acts, in LANGUAGE, MIND, AND KNOWLEDGE 344 (Keith Gunderson ed., 1975), reprinted in JOHN R. SEARLE, EXPRESSION AND MEANING: STUDIES IN THE THEORIES OF SPEECH ACTS 1, 15 (1979); John R. Searle, What is Language?: Some Preliminary Remarks, 11 ETHICS \& POL. 173, 181 (2009). Other speech acts may do even more, as with commissives, performatives, and declarations. See J.L. Austin, How to Do ThINGS WITH WORDS 32-33, 151-57 (1962); Kent Greenawalt, SPEeCH, CRIME, AND the Uses OF LANGUAGE 57-63 (1989). By 'communicate' and its cognates, I mean to capture both the transmission of content as well as the transmission of one's (presumed and often implicit) agreement or belief in that content. Still, despite the familiarity of this use of 'express' in the philosophical literature, I couldn't be more aware that my use of 'express' is not a salutary term in a context in which 'freedom of expression' is right at hand and sometimes is used interchangeably with "freedom of speech." As the better term occurs, so will the substitution.

48. I will not go into detail here about the various fault-lines and strengths of different accounts of this distinction. Rubenfeld's general discussion of the distinction is basically sensible. See Rubenfeld, supra note 12, at 42-44. Articulating the distinction from the perspective of sorting regulations sensitive and insensitive to it, he asks whether the relevant harm that a regulation targets is caused by the communicative aspect of the expressive act or by some other element of it. I defended something like this approach in 
is special. I have argued that speech facilitates some of the core interests of autonomous agents by rendering their mental contents available to others and vice versa, thereby enabling them to know one another, to cooperate with one another, to investigate the world, and to enhance one's understanding of our environment and our circumstances, and thereby enabling (though not ensuring) moral agency.

The external representation of mental content and its communication plays an especially foundational role in furthering these ends in large part because, in general, it is so much more precise and informative than many of its nonessentially communicative, expressive counterparts. I mean something here as mundane as that an explanation of the reasons why one disapproves of another's conduct and a description of the emotional reactions that conduct gives rise to conveys more content than a wordless punch in the nose. Some content conveyed by communication cannot reliably and accurately be conveyed through other means. With respect to the interest in being recognized and known as the person one is and in providing an outlet from the isolation of each mind, curtailments on speech represent a severe incursion on this interest because speech provides unique modes of access to the contents of other minds. I do not mean to include only discursive communication here: a melody or painting of the image in my mind - a external representation of my internal visual imagerymay convey more of my mental contents-including but not limited to my mood - than approving or disapproving behavior; it necessarily conveys more about my private mental contents than silence and its visual analog.

As a general matter, regulations on the non-essentially communicative expression, manifestation or implementation of mental contents as such do not preclude the communication or transmission of the mental contents they express. Restrictions on my ability to express my anger through violence do not preclude my transmitting my anger through communicative means: saying I'm angry, detailing my complaints, and depicting my emotional maelstrom through words, images, or sounds. A restriction on the emotion's non-essentially communicative expression does

Speech, Death, and Double Effect. Shiffrin, supra note 8. I disagree with him in thinking, however, that governmental intent to punish or restrict communication as such is a necessary condition of running afoul of First Amendment protections; we agree that it may be a sufficient condition. See Jed Rubenfeld, The First Amendment's Purpose, 53 STAN. L. REV. 767, 775-78, 793-94 (2001). 
not threaten to isolate me in my mind; a restriction on communication does.

I hasten to add that this general point is perfectly compatible with the recognition that some forms of expression convey more than words, images, or sounds could on certain occasions. It may well be that, on some occasions, the depth of my anger can only be conveyed through violent aggression. I am neither arguing that agents have absolute rights to ensure that (any and all) others fully understand their mental contents on all occasions nor that externalized representations of thoughts always convey more than behavior that acts upon those thoughts in ways different than merely externalizing a representation. But, by and large, speech is special because it is a uniquely specific mechanism for the transmission of mental contents and their discussion, evaluation, development and refinement, independent from and prior to their implementation.

Of course, I do not deny that the transmission of mental contents sometimes immediately affects or implements them: directed at the relevant person, the desire to insult or, in certain contexts, to humiliate or to subordinate can be implemented merely by being communicated. But as a general matter, communicative methods of transmitting mental contents generate the possibility of an intermediate workshop-like space in which one may experiment with, advance tentatively, or try on, revise or reject a potential aspect or element of the self or of one's potential history before directly affirming it through endorsement or implementation. "One cannot preface one's thrown punch with 'maybe' or 'consider the possibility' and thereby make the assault less of a punch in the way that prefatory remarks will qualify a proposition subsequently articulated so that it becomes less than a full-blown assertion. We find both intelligible and significant our abilities effectively to revise, clarify, or even retract what one has begun to say just using further words. ${ }^{50}$ Whereas, I cannot revise or retract my intentional punch by following it immediately with more

49. Nevertheless, on occasion, even purely exploratory communication of thoughts and ideas may have moral significance and may be inappropriate to convey to some people, however explicitly inchoate they are in form.

50. Although sometimes the further speech will have to follow on immediately to be effective as a retraction as opposed to a later rethinking, our linguistic practice allows us to use speech to formulate and even generate our thoughts without the first stab at articulation rigidly gelling immediately into a final draft: we can try on an idea by articulating it without it immediately sticking to us or representing us. Such tentativeness is less possible with most actions (putting aside the special case of speech acts). 
violence, cringing, or even with regretful words. A further stream of punches may clarify my assault was intentional but beyond that rudimentary clarification, further light - why I threw the punch - will typically require words.

The capacity of speech to be tentative and exploratory - to allow us in a non-committal way to try on an idea, whether to formulate it at all or to assess its plausibility or fit with oneselfis closely related to and helps to underpin a more familiar idea about the specialness of speech, namely that we must protect the ability to discuss and conceive of even those actions we may reasonably outlaw, because protecting our speech and conception of them permits us to revisit and justify our regulation; thereby, we may retain the ability to assess the aptness and legitimacy of our regulation and to preserve the ability to change course if we are mistaken.

Not all speech stops short of action and I am not arguing there is an especially clear speech/action divide, but there are some special features that hold generally of speech that render it distinct from other forms of autonomous action that go beyond revelation of mental content. These distinctive features, I submit, play some role in explaining why speech is special and why autonomy accounts, especially those focused on the freedom of thought, may reasonably place a particular premium on preserving and protecting speech. 